\title{
WHAT DO STUDENTS OF A HIGHER EDUCATION INSTITUTION THINK ABOUT FLIPPED LEARNING
}

\author{
Ana Paula Lopes ${ }^{1}$, Filomena Soares ${ }^{2}$ \\ ${ }^{1}$ Polytechnic of Porto (P.PORTO) / ISCAP - CEOS - CEPESE (PORTUGAL) \\ ${ }^{2}$ Polytechnic of Porto (P. PORTO) / ESHT - ESMAD (PORTUGAL)
}

\begin{abstract}
The "Flipped Classroom" or "Inverted Classroom" is a method of blended learning in which the traditional lecture and homework elements of a course are reversed. It is a pedagogical model in which students gain first-exposure learning prior the class and focus on the processing part of learning (open discussions, solving tasks and application problems, clarifying the supporting fundaments, etc.) in class. This implies a much more active role for students and a more challenging mission for lecturers.

Teaching involves not only of the communication of knowledge to students but also demands searching for a better way for knowledge transmission to students in the most effective, significant and technically accessible way. When preparing the Mathematics Zero course we were concerned with which teaching methods were the most appropriate for it. This course was attended by 47 students from Zero Year Course in Institute of Accounting and Administration of Porto (ISCAP) in the 2015/2016 academic year. Several innovation methods were tried, and, in the Spring 2016 semester the "Flipped Learning" model was used.

The purpose of this paper is to present the results of a survey in which students were asked about Flipped Classroom learning as a teaching method, using their experience from the Mathemathics Zero course. How does flipped learning work in practice as a pedagogical model? Would students prefer the traditional way of learning? What do students think about flipped learning as a teaching methodology? These and many other questions will be addressed investigating how the flipping affects student's achievement.
\end{abstract}

Keywords: Online Learning, Flipped Classroom, Higher Education, Video Lectures.

\section{INTRODUCTION}

During the past few years, the educational paradigm has changed from teacher instruction method to student-centered learning. Grounded on this type of innovative model, more technologies have been incorporated into the educational panorama, and several learning methods have provided students quite a few differentiated learning schemes, allowing them to leverage their educational levels by choosing their own tracks [1]. In the middle of the numerous learning approaches, the "flipped classroom" is considered as a potential and amazing learning method, or model, that engages students in applying their learning potential and conducting higher order thinking, instead of using direct teaching instruction ([2], [3], [4]). This model, called "Flipped Classroom", was developed by Jonathan Bergmann and Aaron Sams in 2000 [5], the pioneers of this trend, who at the time were chemistry teachers, at Woodland Park High School in Colorado, in an attempt to counter visible levels of student absenteeism, began to record their lessons and post them online, allowing students to access them remotely. This model has been used by educators at all levels of education, from primary schools and upper secondary schools to the most reputable higher education institutions in the world, such as Harvard, Massachusetts Institute of Technology (MIT), among others. Thus, the principal idea comes from reversing the traditional teaching paradigm, where the main phases of the teaching and learning process, such as classroom activities and homework, are reversed. The flipped classroom is then settled as a different course organization: where instructional content (e.g., pre-recorded video lectures) is assigned as "homework" - analyzed before coming to class and in-class time is spent working on problems, advancing concepts, and engaging in collaborative learning [6]. The flipped classroom may contain a big array of out-of-class activities further than lectures, including readings, homework, and supplemental videos ([7], [8], [9]). In-class activities differ widely, including activities such as role-play, debates, quizzes, and group presentations, amongst others [10]. Several studies have shown positive effects of the flipped classroom model in teaching and learning activities ([11], [12], [13], [14], [15], [16]). In addition, the flipped classroom model allows the learners to learn at their 
own pace. On the outcome of his experience, Tucker [17] has shown how Flipped Classroom leads (if properly designed/evaluated) to improve teaching-learning relationships producing a greater involvement and commitment of the students and a higher motivation as well.

Mathematics is one of the most important subjects; however higher education institutions (HEI) are currently facing many unprepared students regarding mathematical skills and therefore Mathematics teachers are dealing with one of the major challenges: the use of educational technology across the mathematics programs in order to improve the performance of their students. Although students avoid Mathematic courses, nevertheless Science, Technology, Engineering and Mathematics (STEM) fields keep among the job-growth areas. According to Wilkins [18] "In the present quantitatively complex society, a person needs a functional knowledge of mathematical content to make informed decisions as a citizen and as a worker".

The purpose of this study was to introduce a research that was done in the 2015/2016 academic year in a Mathematics Zero Course at Institute of Accounting and Administration of Porto (ISCAP) in which flipped learning was used, in particular, the experience of students being taught by using flipped learning and what it can tell us about the relevance of flipped learning in higher education. In our opinion, as modern technology allows lecturers to provide course learning materials in a variety of digital support forms, which are available to students "on demand", the results of this study could also easily be extended to the instruction of other subjects.

\section{METHODOLOGY}

As it was already mentioned, this paper intends to assess the impact of the flipped model on teaching strategies implemented in the course Mathematics Zero. To achieve this, a diverse range of data collection instruments were used. In this way, we tried to get a more comprehensive set of information that, upon examination, can corroborate the same phenomenon [19]. The teaching structure of the course was changed to apply the flipped learning ideology. For a good development of the application of teaching based on Flipped learning it is necessary to elaborate and organize all the didactic materials to be used by the students as well as to establish a clear sequential learning plan. The MOOC "Mathematics without STRESS" (or in its original version - in Portuguese - Matemática 100 STRESS - M100S) hosted in the online platform OpenED (created by the e-Learning Unit from Polytechnic of Porto), www.opened.ipp.pt, and the online MatActiva Project, www.matactiva.com, have been used in this event. The study material was organized through the by means of Learning Modules hosted in the "Content" section of the first course - Probability and Combinatorics, from M100S.

Mathematics without STRESS, currently has three different Courses: Probability and Combinatorics, Introduction to Differential Calculus and Trigonometry and Complex Numbers.

All these courses are created using the same guidelines based on the following division:

- Information Spot

- Math Diagnostic Test (MDT) - entry test, not mandatory;

- Modular subject division with two distinct subsections:

- Video-lectures

- Sequential mini-quizzes;

- "Doubt Ed" - Open Discussion forum;

- Final "Assessment Test"

- Global Course evaluation

The first course - Probability and Combinatorics (PC) - the one used in this work, embraces 19 different modules/lessons, with 19 randomized quizzes and 24 video-lectures, distributed by the following topics:

- Random Experiment and Sample Space

- Probability and Properties of Probability

- Conditional Probability

- Law of Total Probability and Bayes Theorem
- Events and Operations on Events

- Exclusive Events

- Intersection Events

- Independent Events 
- Fundamental Counting Principle

- Arrangement without repetition

- Permutations

- Pascal's Triangle

- Probability Distribution

- Normal Model.
- Factorial of a Natural Number

- Arrangement with repetition

- Combinations

- Newton's Binomial Formula

- Binomial Model

The main page of the PC course is presented in Fig. 1.

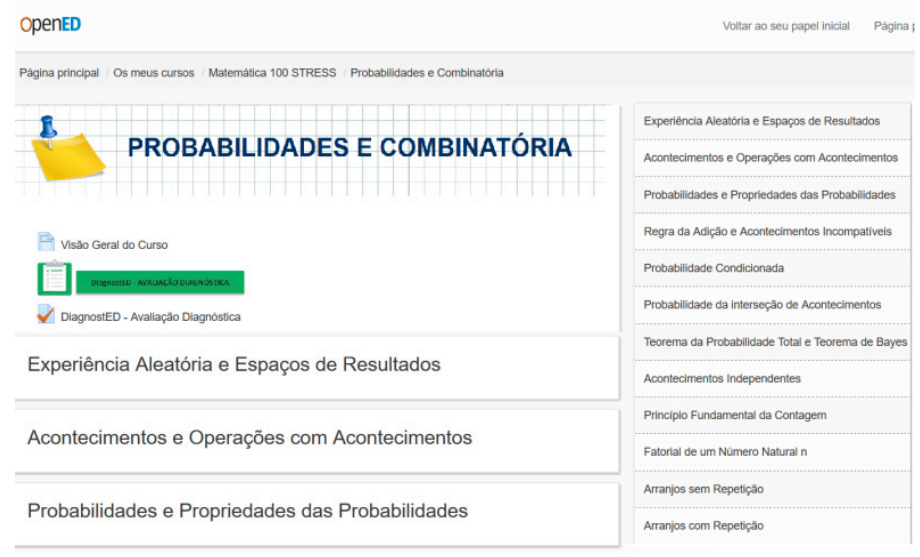

Figure 1. PC Course main page screenshot

Students could also found texts, videos, links to external websites, links to documents from the Mathematics Zero Course, etc, in the online MatActiva Project.

A total of 47 students from Zero Year Course participated in this study, divided into experimental and control groups. The experimental group (15) was taught Probability and Combinatorics using the flipped classroom method, while the control group (32) was taught by traditional teaching methods. The traditional classes were provided with in-class lectures by the professor. This lecture typically lasted the entire 90 minutes of class, two times a week. In general, one sub-section took two or three weeks to complete. Once a sub-section was completed, students had a test with six questions directly related to theory and examples covered during the lectures. The flipped class was scheduled one day per week for 90 minutes per class. Students of the flipped class were required to view one to six short lecture videos, each lasting between five to eight minutes, prior to the class meeting. The theory and examples found in the video lectures were similar to those presented in the lecture classes. The videos and playlists for M100S course can be found in the link:

https://www.youtube.com/channel/UCwNMLB6X3VJG7da6hXI4kiw. During the flipped presential sessions, additional problems were worked in small groups, and the professor observed and supported student participation and progress, corrected students if errors were seen, and answered questions as they arose. Mostly, the solutions were presented first by students and occasionally by the professor if a problem was found to be too hard for them. Sometimes students were asked, in the flipped class, to develop and record their own videos of working examples, so later it gives the possibility to the professor review these. Like in the traditional classes, once a sub-section was completed, students had a test with six questions on material directly related to theory and examples covered in the video-lectures. Although these video lectures were short (8 minutes maximum), we introduced, several small group of questions and exercises, to be answered by students before continuing the video visualization in order to create some interaction, promote student engagement and, simultaneously, help them to overcome the tendency to be overconfident in their learning judgment (see some research results in [20]). Frequently, at the beginning of the class, several questions were straightly answered, related to an item in the video, but a lecture was never taught by the professor in the class. Both classes, traditional and flipped, were given the same tests, online homework and written homework. The only pedagogical difference among these students' segments was the instruction's method. 
At the end of the academic year, a survey was conducted, aiming to analyze the experience of students exposed to the flipped learning system. The main purpose for the survey was to get an answer to the question as to whether it is possible to use the flipped learning methodology in higher education from a student's perspective. Students were asked about flipped learning as a teaching method in higher education, using their experience from the Mathematics Zero course, their experience with the online lectures and the group sessions they took part in and how they valued the course overall.

A LimeSurvey questionnaire of 12 questions was created in Moodle, the survey was anonymous and from the 15 students ( 9 male and 6 females) from experimental group, 15 answered it with response rate of 100 percent. Thus the survey was statistically significant. The data were then applied for analysis.

In this questionnaire there were 2 base questions about age and gender, 8 multiple-choice questions and 2 open questions. For the purpose of this study, five significant questions were highlighted and essentially intended to:

a) know what the students think about flipped model as a teaching methodology at the higher education;

b) identify the students' satisfaction level with the assignments that were given;

c) identify how do students value the video lectures (produced by M100S) that they watched;

d) recognize the importance of solved exercises (step by step) for the students;

e) know whether students would prefer a flipped Math class over a traditional Math class.

\section{RESULTS}

The questions were based in the reliability tests by UMASS's research team - The SimCalc Research team of the Kaput Center, University of Massachusetts Dartmouth - about Measuring Student Attitude in Mathematics Classrooms [21]. We used a 5 point Likert scale, "1" represented Strongly Disagree and " 5 " represented Strongly Agree, to maintain stability given the intuitive understanding and insight of attitude concerning certain activities measured by several items.

The main objective of this survey was to find out the relevance of using the flipped learning methodology in higher education. One of the questions the students were asked was: "Do you think flipped learning is an appropriate method for teaching in higher education?" (Q1)

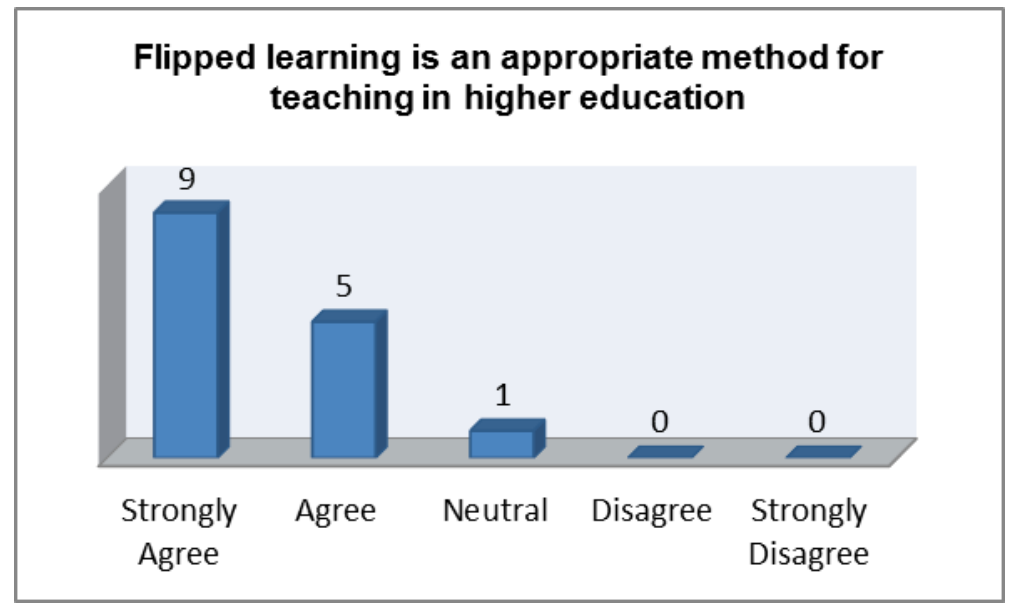

Figure 2. Registered answers to Q1

As it can be seen, 14 of 15 students $(93,3 \%)$ found the flipped method an appropriate one based on their experience from the course. No one disagreed and one was neutral. In terms of age, we find that all age groups are satisfied with the result, but we can see a minor movement in the direction of the notion that: the older the student, the "happier" he is with this method of teaching. Of students 20 years or younger, 8 of 9 , or $88,9 \%$ percent, strongly agreed or agreed that flipped learning is an 
appropriate method for teaching in higher education, while in the age group of 20-23 years old, 4 of 4 strongly agreed and 2 of 2 in the age group of 23-26 years old strongly agreed.

Since in the flipped model student assignments were tasks requiring student engagement and the presentation of a final tangible "product", enabling students' learning and skills assessment, it was important to analyse the contentment with the assignments undertook. In this sense, students were asked: "Are you satisfied with the assignments that were given?"(Q2).

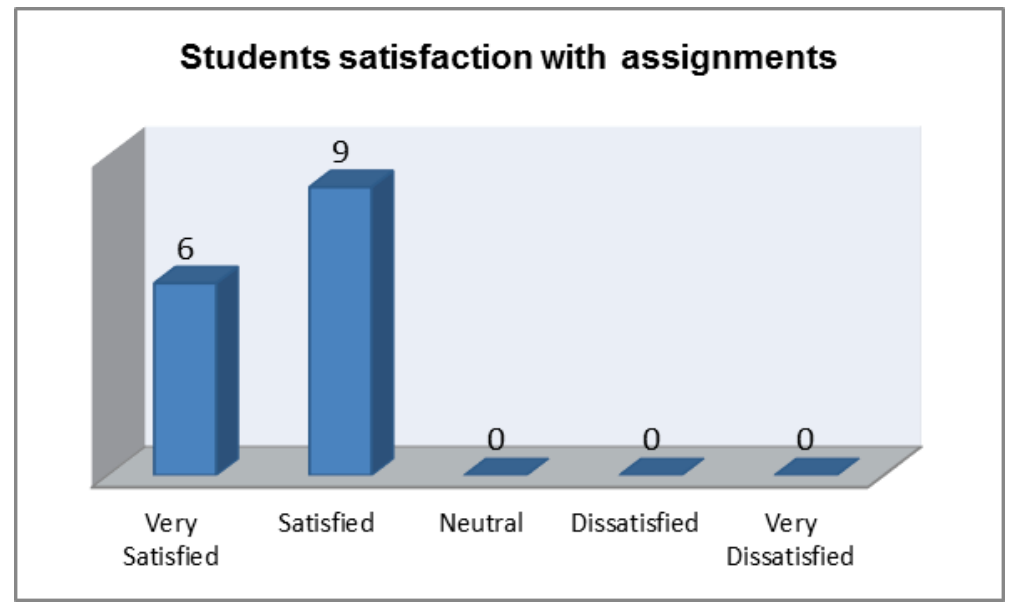

Figure 3. Registered answers to Q2

The results presented show that 15 of the 15 students $(100 \%)$ were very satisfied or satisfied with the assignments given.

An extremely important part of the flipped learning methodology are the video lectures, produced by M100S, where the relevant concepts are exhibited along with some illustrative examples, these take 5-10 minutes and are well-defined and easy to watch. It is important to remember that the students are comparing the use of video lectures with traditional lectures. Students were asked how they rate the video lectures in the course (Q3).

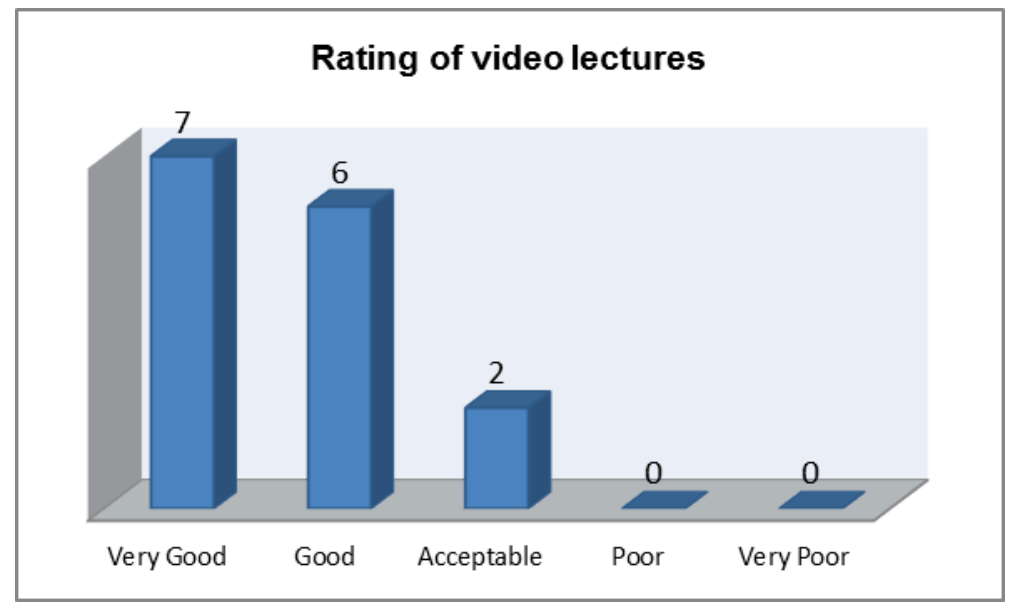

Figure 4. Registered answers to Q3

The results presented in Figure 4 reveal that students gave a good classification to the video lectures, 7 of 15 students $(46,7 \%)$ are of opinion that video lectures are very good; $40 \%$ of the students think that video lectures are good; and only 2 students consider that video lectures are acceptable. No one think that video lectures are poor or very poor.

After watching each video (playing and replaying it as many times as they please), students can take a small quiz, with 5 random questions, and apply the concepts addressed in video lectures. In relation to these small quizzes, students can have multiple attempts at each one of them. This can help to transform the quiz taking process into an educational activity instead of a simple assessment. As the 
quiz is randomized, the student will get a new version in each attempt, which will be useful for practice purposes. Feedback is provided for each question, allowing the students to see one (of the possible) proposed solution, step by step. The Pool of Questions, from which the quizzes are randomised, is categorized separately by learning items (modules), as well as subdivided in difficulty levels. Students were asked how they rate the importance of feedback on the exercises in the course (Q4).

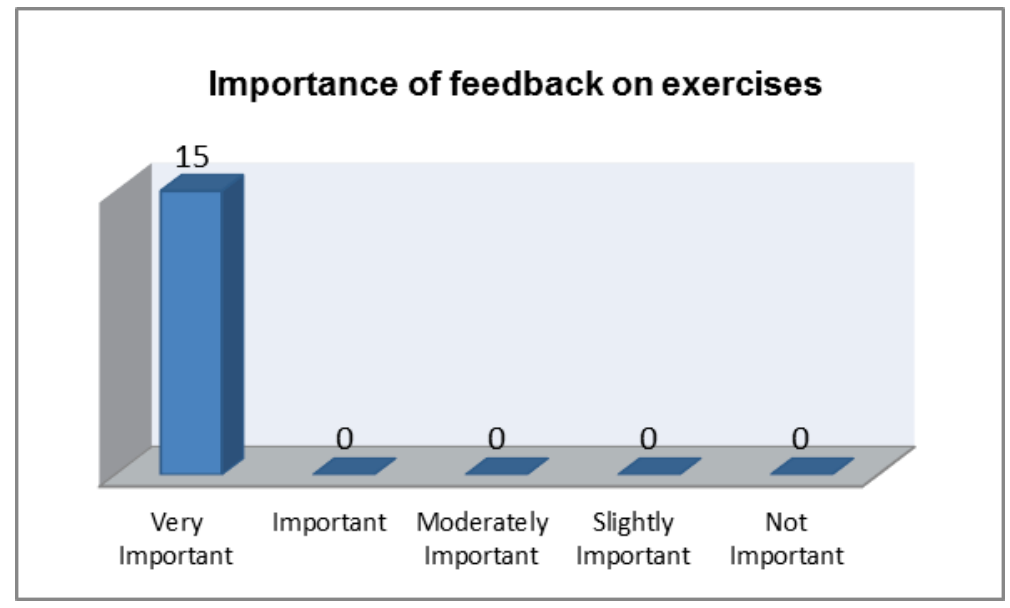

Figure 5. Registered answers to Q4

Figure 5 shows that all the students consider that the feedback provided for each question, allowing the students to see one (of the possible) proposed solution, step by step it is very important.

Finally, it was important to know whether students would prefer a flipped Math class over a traditional Math class. Therefore, students were asked to how do they rate the flipped instruction in a direct comparison with traditional instruction (Q5).

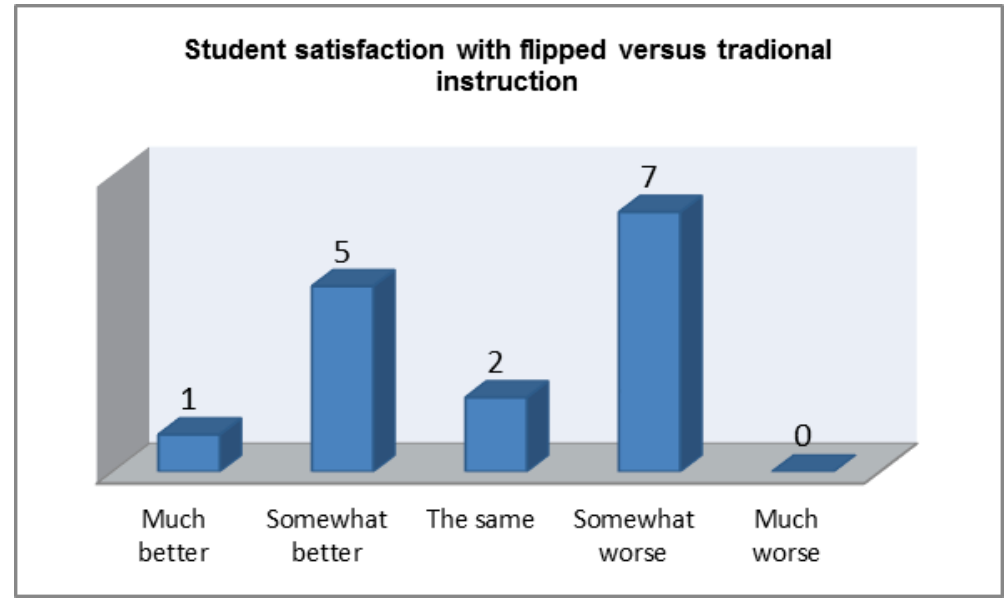

Figure 6. Registered answers to Q5

It is interesting, and even surprising, to see that $46,7 \%$ of the students consider that the flipped educational model in somewhat worse than the traditional educational model (Fig.6).

From the open questions where the students could leave their comments about this flipped model applied in the Mathematics Zero Course, one the most interesting findings was that students liked the video lectures, most of them said they were clear and the topic was very well explained, always with some examples; however, several students indicated that they would prefer to be taught by the professor in person, at the class. For them in the flipped classroom students take responsibility for their own learning, and it is a good model because when students are sick at home, they don't get left behind. With this model all students are engaged in their learning. 


\section{CONCLUSIONS}

The purpose of this research was to get a student's perspective on the relevance of using flipped learning model at the higher education. We can consider that the experience was very positive, almost all students, in the Mathematics Zero Course felt that the flipped learning model was an appropriate method at the higher education level (Fig. 2). However, surprisingly, despite the high satisfaction levels with all the work, materials and tasks presented and developed, students seem a bit reluctant to validate the methodology itself, feeling that for all intents and purposes their performance and level of learning attained is almost, and exclusively, their own responsibility. It should be noted that this model seems to hamper the frequent blame of teachers for the lack of success of their students.

This study also reflects a design and a development research study of a teaching model across several topics of a Mathematics Zero Course. The product of this research is an explicit teaching model that can be applied by other courses.

In future we would like to continue to study this classroom teaching model and expand it to other mathematics course at ISCAP as well with other professors. This research provides, however, only one point of view in the discussion of the theory of flipped learning, the perspective of the student in higher education. Additional research will then be conducted from the perspective of the instructor as well as to look at how flipped learning works in different study fields/academic subjects.

\section{REFERENCES}

[1] Li, N., Verma, H., Skevi, A., Zufferey, G., Blom, J., \& Dillenbourg, P. (2014). Watching MOOCs together: investigating co-located MOOC study groups. Distance Education, 35(2), 217 - 233.

[2] Davies, R. S., Dean, D. L., \& Ball, N. (2013). Flipping the classroom and instructional technology integration in a college-level information systems spreadsheet course. Etr \& DEducational Technology Research and Development, 61(4), 563 - 580.

[3] Lopes, A.P., Soares, F., (2017). "Flipped Classroom With a MOOC" An E-Learning Model into a Mathematics Course. In 11th International Technology, Education and Development Conference - INTED2017 Proceedings, 6th-8th March 2017, Valencia, Spain, Pages: 46434649, ISBN: 978-84-617-8491-2, ISSN: 2340-1079, doi: 10.21125/inted.2017.1092.

[4] Flumerfelt, S., \& Green, G. (2013). Using lean in the flipped classroom for at risk students. Educational Technology \& Society, 16(1), 356 - 366.

[5] Bergmann, J., \& Sams, A. (2012). Flip Your Classroom: Reach Every Student in Every Class Every Day. Arlington: ISTE.

[6] Findlay-Thompson, S., \& Mombourquette, P. (2014). Evaluation of a flipped classroom in an undergraduate business course. Business Education and Accreditation, 6, 63-71.

[7] Bergmann, J., Overmyer, J., \& Wilie, B. (2013, July 9). The Flipped class: Myths versus reality [Web log post]. Retrieved from http://www.thedailyriff.com/articles/the-flipped-classconversation-689.php.

[8] Chen, Y., Wang, Y., Kinshuk, \& Chen, N. S. (2014). Is FLIP enough? or should we use the FLIPPED model instead? Computers and Education, 79, 16-27. doi:10.1016/j.compedu.2014.07.004.

[9] Fautch, J. M. (2015). The Flipped classroom for teaching organic chemistry in small classes: Is it effective? Chemistry Education Research and Practice, 16(1), 179-186. doi:10.1039/c4rp00230j.

[10] O'Flaherty, J., \& Phillips, C. (2015). The use of flipped classrooms in higher education: a scoping review. The Internet and Higher Education, 25, 85-95.

[11] Davies, R. S., Dean, D. L., \& Ball, N. (2013). Flipping the classroom and instructional technology integration in a college-level information systems spreadsheet course. Educational Technology Research and Development, 61, 563-580. doi:10.1007/s11423-013-9305-6.

[12] Mason, G. S., Shuman, T. R., \& Cook, K. E. (2013). Comparing the effectiveness of an inverted classroom to a traditional classroom in an upper-division engineering course. IEEE Transactions on Education, 56(4), 430-435. doi:10.1109/TE.2013.2249066. 
[13] Missildine, K., Fountain, R., Summers, L., \& Gosselin, K. (2013). Flipping the classroom to improve student performance and satisfaction. Journal of Nursing Education, 52(10), 597-599. doi:10.3928/01484834-20130919-03.

[14] Fautch, J. M. (2015). The Flipped classroom for teaching organic chemistry in small classes: Is it effective? Chemistry Education Research and Practice, 16(1), 179-186. doi:10.1039/c4rp00230j.

[15] Hung, H.-T. (2015). Flipping the classroom for English language learners to foster active learning. Computer Assisted Language Learning, 28(1), 81-96. doi:10.1080/09588221.2014.967701.

[16] Schultz, D., Duffield, S., Rasmuseen, S. C., \& Wageman, J. (2014). Effects of the flipped classroom model on student performance for advanced placement high school chemistry students. Journal of Chemical Education, 91(9), 1334-1339. doi:10.1021/ed400868x.

[17] Tucker, B. (2012) The flipped classroom. Retrieved from http://educationnext.org/the-flippedclassroom.

[18] Wilkins, J. L. M., \& Ma, X. (2003). Modeling change in student attitude toward and beliefs about mathematics. The Journal of Educational Research, 97(1), 52-63. doi:10.1080/00220670309596628.

[19] R. K. Yin, (2010). Estudo de caso: planejamento e métodos. Porto Alegre, Brasil: Bookman, 2010.

[20] Szpunar, Karl K., Jing, Helen G. and Schacter, Daniel L.(2014) Overcoming overconfidence in learning from video-recorded lectures: Implications of interpolated testing for online education, Journal of Applied Research in Memory and Cognition, 3 (2014) pp 161-164. http://dx.doi.org/10.1016/j.jarmac.2014.02.001

[21] Brookstein, A., Hegedus, S., Dalton, S., Tapper, J. and Moniz, R. (2011). Measuring Student Attitude in Mathematics Classrooms. University of Massachusetts Dartmouth. Retrieved from http://www.kaputcenter.umassd.edu/downloads/products/technical_reports/tr4_student_attitude. pdf 